\title{
Evaluation of the Mode of Referral of Patients for Physiotherapy by Physicians
}

\author{
Odebiyi, D.O. ${ }^{1}$, Amazu, A.R. ${ }^{1}$, Akindele, M.O. ${ }^{2}$, Igwe, S.E. ${ }^{3}$, Olaogun, M.O.B. ${ }^{4}$ \\ ${ }^{1}$ Department of Physiotherapy, College of Medicine University of Lagos, Lagos \\ ${ }^{2}$ Department of Physiotherapy, College of Medicine, University of Kano, Kano \\ ${ }^{3}$ Department Medical Rehabilitation, College of Medicine, University of Nigeria Nsukka, Enugu \\ ${ }^{4}$ Department Medical Rehabilitation, College of Health Sciences, Obafemi Awolowo University, Ile-Ife \\ Correspondence \\ Dr. Daniel O Odebiyi・Email: femiodebiyi@yahoo.com
}

\begin{abstract}
SUMMARY
The physiotherapy profession has emerged not only as an important medical and rehabilitation complement in health care delivery but also as a vital therapeutic tool with defined scientifically based protocols. In Nigeria, it is used as a prescription rather than as a referral, on a consultation basis, but its use as a prescription is gradually being discouraged in some developed countries. There seems to be a low level of aw areness of this development, particularly in the developing countries. This study was therefore designed to evaluate the physicians' mode of referral of patients for physiotherapy in Nigeria.

A total of 1192 physicians participated in the survey, a 78 per cent response rate. They were required to complete a 22 -item self developed closed-ended questionnaire using a sample of opportunity. The questionnaire obtained information on demographic data, educational attainment, university of graduation, year of graduation and mode of referral for physiotherapy.

A total of $1054(88.4 \%)$ respondents agreed that physiotherapists were trained enough to make clinical decisions on the treatment of their patients and $678(56.9 \%)$ referred patients for physiotherapy. Of the respondents who agreed that physiotherapists are trained well enough to make clinical decisions on the treatment of their patients, $786(74.6 \%)$ graduated from universities that also have a physiotherapy training programme. The majority $442(68.2 \%)$ of these respondents and $603(79.4 \%)$ of the respondents who received some form of lectures in physiotherapy during their medical training or whose universities had a physiotherapy training programme did not include prescriptions in their referrals.
\end{abstract}

KEY WORDS: physicians, mode of referral, physiotherapy

\section{INTRODUCTION}

Physiotherapy has been defined as a dynamic health care profession with established theoretical and widespread clinical applications (which are mostly physical approaches) in the preservation, development and restoration of optimal physical functions (Wallace, 2003). As a science-based allied medical field, it has emerged not only as an important medical and rehabilitative complement in health care delivery but also as a health profession with a vital therapeutic tool that employs defined scientifically-based protocols, and is an integral part of the treatment of most patients (American Physical Therapy Association, 1997). It is widely used in health institutions, private practices, schools, sports and work place settings (Hogue, 2005). Physiotherapists are primary healthcare professionals concerned with the assessment, diagnosis, treatment and prevention of the dysfunction and impairment of movement in people of all ages and within a wide range of contexts (McMeeken et al., 2005).

Physicians have profound influence on other health professions including physiotherapy as they are at the 'top of the pyramid' of health care professionals (Silva, 2005). Generally, patients still rely on physicians for recommendation to other health care professionals. Medical referrals serve not only as a tool for communication, but as an indicator of the level of awareness of physiotherapy by referring health care professionals (Quartey, 2009). The practice of physiotherapy as a 'prescription' rather than as a referral, on a consultation basis, is now discouraged in some developed countries. In the United Kingdom for instance, first contact physiotherapy practice is now allowed only 
during emergency situations or in cases where the physiotherapist has direct access to the patient's physician (Biddle, 1900). On the other hand, first contact physiotherapy is now practised by the Australian Physiotherapy Association (Gallery, 1997; Sheppard, 1994).

The practice of physiotherapy as a first contact profession is not common in Nigeria. Physiotherapists often mainly depend on referrals from physicians from the different fields of practice of medicine. The practice of 'prescribing physiotherapy' by most physicians has been of great concern to physiotherapists' worldwide (Balogun, 1998; Struber, 2003). In a survey involving 151 physicians in California, it was reported that 83.4 per cent of physicians used physiotherapy as a 'prescription' rather than as a referral (Silva, 2005). Unfortunately, these prescriptions are often wrong (Ross, 2000; Dickson, 2001). This practice of including the prescription of modalities in the referral for physiotherapy is an indication of the wrong attitude and/or poor knowledge by these physicians about the role of physiotherapy in health care delivery (Dunkel, 2004; Savinor and Shepherd, 2004).

Balogun (1998) observed that the greatest challenge facing physiotherapists in Nigeria is educating the masses and other healthcare providers on the role of physiotherapy in health care delivery. According to Jackson (2004), lack of or poor knowledge about a profession may lead to misconceptions about the profession and inter-professional conflicts. Thus, good awareness of the role of physiotherapy in health care delivery may influence its use (Jackson, 2004). The university of graduation of the physician has been identified as an important factor which may influence physicians' knowledge of physiotherapy (Ross, 2000). The present study was therefore designed to evaluate physicians' mode of referral of patients for physiotherapy in Nigeria. It also examined the factors responsible for the mode of referral.

\section{MATERIALS AND METHOD}

\section{Participants}

The respondents for this study were physicians who were practising in various facilities in Nigeria and who had at least two years post-qualification experience. They included all grades of physicians from different specialties and were recruited from physicians attending practice meetings in three study centres in Nigeria - Lagos, Nsukka and Kano.

\section{Questionnaire Design}

The questionnaire was self developed and was adapted from two similar works titled 'challenges and responsibilities of the physiotherapist as a first contact practitioner' and 'changing the public perception of physiotherapeutic treatment' respectively (Gallery, 1997; Lee and Sheppard, 1998). The questionnaire had 22 items that comprised seventeen close-ended questions and five open-ended questions and was divided into three sections A, B and C. Section A collected information on personal characteristics such as: age, gender, marital status, religion and state of origin. Section B collected information on educational attainment, university of graduation, year of graduation, working relationship with physiotherapists, and mode of referral for physiotherapy. Section C collected information on the rate and mode of referral of patients for physiotherapy. Prior to the survey, to ascertain content validity, three copies of the initial draft of the questionnaire were sent to two physiotherapy educators from the University of Lagos and one experienced physiotherapist (clinician) from the Lagos University Teaching Hospital, who are experts in questionnaire design. The questionnaire was then pilot tested on 10 practising physicians to ensure that the questions were clearly stated and would be easily understood by the respondents.

\section{Questionnaire Administration}

The aim and objectives of the study were clearly stated in a cover letter attached to each copy of the questionnaire in order to obtain the consent of respondents, and only those who consented were required to complete the questionnaire. One thousand five hundred $(1,500)$ copies of the questionnaire were distributed using sample of opportunity i.e, participants were selected from a group who were available at the time of the study (i.e., physicians attending practice meetings).

\section{Data Analysis}

The data obtained were presented using descriptive statistics of frequency and percentage, bar chart, mean and standard deviation using the software package Microsoft Excel.

\section{RESULTS}

One thousand one hundred and ninety two $(1,192)$ physicians comprising 807 females $(67.7 \%)$ and 385 males $(32.3 \%)$, participated in the study. Their ages ranged between 24 and 63 years with a mean age of $43.2 \pm 1.4$ years. 
Almost half of the respondents (48\%) were from the southwest geo-political zone (figure 1). The frequency distribution of the respondents' first contact with physiotherapist(s) is shown in figure 2. When the respondents were asked about their view of physiotherapy as a course, the majority of the respondents, 930 (78\%) were of the opinion that physiotherapy is a professional course. Seven hundred and fifty one $(63.0 \%)$ respondents viewed physiotherapy as both an arts and a science discipline while 15 per cent considered it to be more of an arts than a science discipline. The remaining 22 per cent viewed it to be more of a science than an arts discipline.

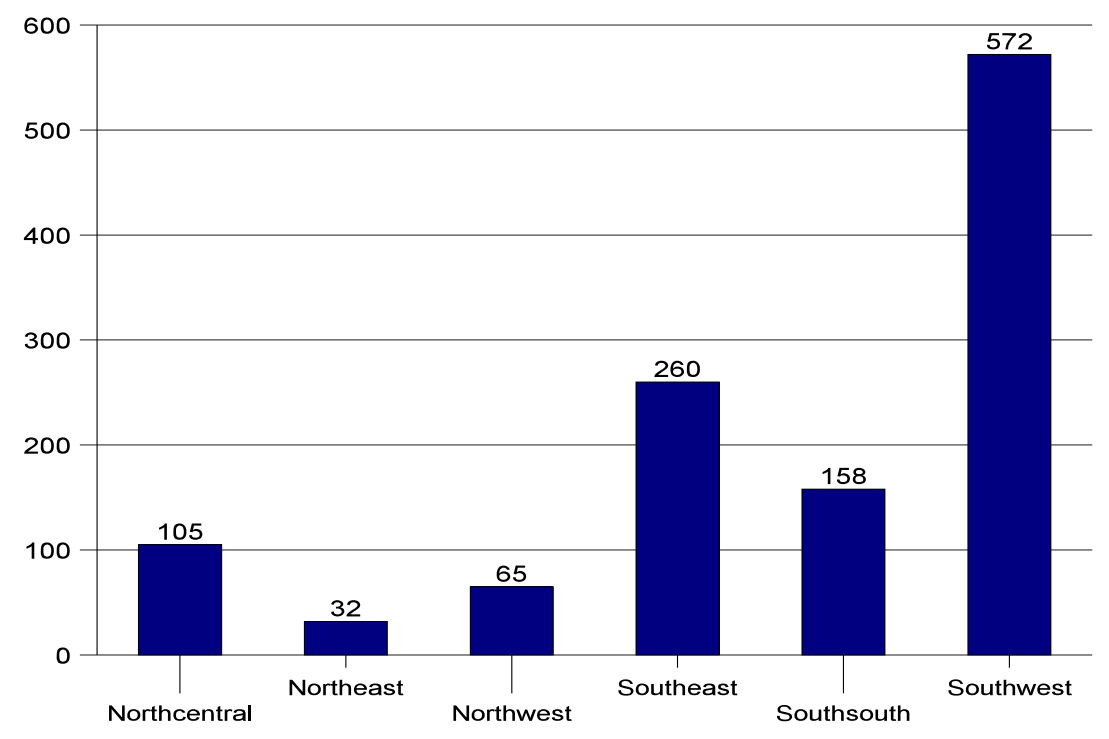

Figure 1. Frequency distribution of respondents' geopolitical zones

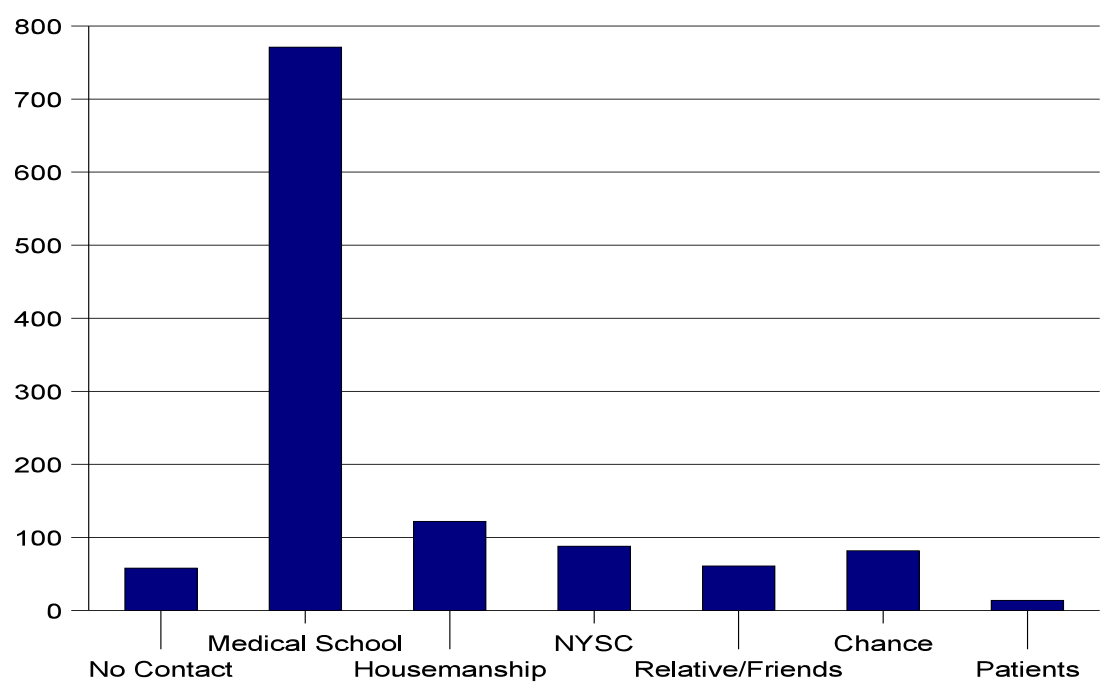

Figure 2. Frequency distribution of respondents' first contact with physiotherapists 


\section{The Influence of Medical School of Graduation}

Table 1 shows the university of graduation of the physicians with or without physiotherapy training. Six hundred and forty eight $(54.4 \%)$ of the respondents graduated from universities with a physiotherapy training programme. The remaining respondents, $544(45.6 \%)$ had no physiotherapy training. The majority $1054(88.4 \%)$ of the respondents agreed that physiotherapists are trained enough to determine the right treatment for their patients whilst 138 $(11.6 \%)$ thought otherwise. Of the 1054 (88.40\%) respondents who felt that physiotherapists are trained enough to determine the right treatment for their patients, $786(74.6 \%)$ graduated from universities with a physiotherapy training programme. The majority, 442 $(68.2 \%)$ of the respondents who graduated from universities with a physiotherapy training programme did not include prescription in their referrals for physiotherapy while the majority $481(88.40 \%)$ of those who graduated from universities without physiotherapy training programme included prescription in their referrals (table 1).

\section{The Influence of Previous Physiotherapy Lectures}

The majority of the respondents 603 (79.4\%) who received some form of lectures in physiotherapy during their medical training did not include prescription in their referrals for physiotherapy while the majority of the respondents, $300(69.4 \%)$, who did not receive lectures in physiotherapy during their medical training, included prescription in their referrals for physiotherapy (table 1). Of the respondents who received some form of lectures in physiotherapy during their medical training, only 185 $(30.7 \%)$ reported that the lectures were not beneficial to their medical practice while the majority 418 (69.3\%) reported that the lecture was beneficial to their medical practice. The majority $468(61.6 \%)$ of the respondents who received physiotherapy lectures during their medical training, referred patients for physiotherapy while only 210 $(48.7 \%)$ of those who did not receive physiotherapy lectures during their medical training referred patients for physiotherapy (table 2). Of the respondents who referred patients for physiotherapy, $123(58.5 \%)$ of those who did not receive lectures in physiotherapy during their medical training and $93(25.3 \%)$ of those who did, rarely referred patients for physiotherapy (table 2). Also 257 (54.9\%) and $76(36.2 \%)$ of those who received lectures in physiotherapy during their medical training and those who did not occasionally referred patients for physiotherapy respectively while $118(25.3 \%)$ and $11(5.3 \%)$ of those who did and those who did not receive lectures in physiotherapy respectively, during their medical training regularly referred patients for physiotherapy (table 2).

Table 1. Physiotherapists' ability to deduce treatment and influence the previous physiotherapy lecture and university of training on respondents' mode of physiotherapy referral

\begin{tabular}{|c|c|c|c|c|c|c|}
\hline & \multicolumn{2}{|c|}{ Total } & \multicolumn{2}{|c|}{$\begin{array}{c}\text { Universities with No PT } \\
\text { Training }\end{array}$} & \multicolumn{2}{|c|}{ Universities with PT Training } \\
\hline & $\mathrm{N}$ & $\%$ & $\mathrm{~N}$ & $\%$ & $\mathrm{~N}$ & $\%$ \\
\hline Universities of Graduation & 1192 & 100.00 & 544 & 45.60 & 648 & 54.40 \\
\hline \multicolumn{7}{|l|}{ Ability to Deduce Patients' Treatment } \\
\hline - Yes & 1054 & 88.40 & 268 & 25.40 & 786 & 74.60 \\
\hline - No & 138 & 11.60 & 99 & 71.60 & 39 & 28.40 \\
\hline \multirow[t]{2}{*}{ - Total } & 1192 & 100.00 & 367 & 30.79 & 825 & 69.21 \\
\hline & \multicolumn{6}{|c|}{ Mode of Physiotherapy (PT) Referral } \\
\hline \multirow[t]{2}{*}{ Previous Physiotherapy Lecture: } & \multicolumn{2}{|c|}{ Total } & \multicolumn{2}{|c|}{ Include Prescription } & \multicolumn{2}{|c|}{ No Prescription } \\
\hline & $\mathrm{N}$ & $\%$ & $\mathrm{~N}$ & $\%$ & $\mathrm{~N}$ & $\%$ \\
\hline - Received physiotherapy lecture & 760 & 100.00 & 157 & 20.60 & 603 & 79.40 \\
\hline - No physiotherapy lecture & 432 & 100.00 & 300 & 69.40 & 132 & 30.60 \\
\hline - Total & 1192 & 100.00 & 457 & 40.10 & 735 & 59.90 \\
\hline \multicolumn{7}{|l|}{ Graduation from Universities: } \\
\hline - With physiotherapy training & 648 & 100.00 & 206 & 31.80 & 442 & 68.20 \\
\hline - No physiotherapy training & 544 & 100.00 & 481 & 88.40 & 63 & 11.60 \\
\hline - Total & 1192 & 100.00 & 624 & 53.35 & 568 & 47.65 \\
\hline
\end{tabular}


Odebiyi, Amazu, Akindele, Igwe, Olaogun

Table 2. Frequency Distribution of the Influence of Physiotherapy Lecture during Medical Training on Physiotherapy Referrals Rate

\begin{tabular}{|c|c|c|c|c|c|c|c|c|c|c|}
\hline & \multicolumn{10}{|c|}{ Frequency Distribution of Physiotherapy Referrals Rate } \\
\hline & \multicolumn{4}{|c|}{ TOTAL } & \multicolumn{3}{|c|}{ YES } & \multicolumn{3}{|c|}{ NO } \\
\hline & \multicolumn{2}{|c|}{$\mathrm{N}$} & \multicolumn{2}{|c|}{$\%$} & \multicolumn{2}{|c|}{$\mathrm{N}$} & $\%$ & $\mathrm{~N}$ & & $\%$ \\
\hline $\begin{array}{l}\text { Physiotherapy lecture during medical } \\
\text { training: }\end{array}$ & \multicolumn{2}{|c|}{1192} & \multicolumn{2}{|c|}{100} & \multicolumn{2}{|c|}{760} & 63.8 & 432 & & 36.2 \\
\hline $\begin{array}{l}\text { Percentage physiotherapy referral: } \\
\text { - Received physiotherapy lecture } \\
\text { - No physiotherapy lecture } \\
\text { - Total }\end{array}$ & \multicolumn{2}{|c|}{$\begin{array}{l}760 \\
432\end{array}$} & & $\begin{array}{l}0.00 \\
0.00 \\
0.00\end{array}$ & $\begin{array}{l}46 \\
21 \\
67\end{array}$ & & $\begin{array}{l}61.60 \\
48.70 \\
56.90\end{array}$ & $\begin{array}{c}292 \\
222 \\
514\end{array}$ & & $\begin{array}{c}38.40 \\
51.30 \\
43.10\end{array}$ \\
\hline \multirow{2}{*}{$\begin{array}{l}\text { Rate of patient referral for } \\
\text { physiotherapy }\end{array}$} & \multicolumn{2}{|c|}{ Total } & \multicolumn{2}{|c|}{ Not at all } & \multicolumn{2}{|c|}{ Rarely } & \multicolumn{2}{|c|}{ Occasionally } & \multicolumn{2}{|c|}{ Regularly } \\
\hline & $\mathrm{N}$ & $\%$ & $\mathrm{~N}$ & $\%$ & $\mathrm{~N}$ & $\%$ & $\mathrm{~N}$ & $\%$ & $\mathrm{~N}$ & $\%$ \\
\hline - Received physiotherapy & $\begin{array}{l}760 \\
432\end{array}$ & 63.80 & 292 & 38.40 & $\begin{array}{r}93 \\
123\end{array}$ & $\begin{array}{l}19.80 \\
5850\end{array}$ & $\begin{array}{r}257 \\
76\end{array}$ & 54.90 & 118 & $\begin{array}{r}25.30 \\
5.30\end{array}$ \\
\hline - Total & 1192 & 100.00 & 524 & 43.10 & 216 & 18.10 & 333 & 27.90 & 129 & 10.80 \\
\hline
\end{tabular}

\section{DISCUSSION}

This study was designed to evaluate the mode of referral of patients for physiotherapy by physicians in Nigeria and the possible factors responsible for their mode of referral for physiotherapy. The finding that the majority of the respondents were from the south-west geo-political zone may be due to the fact that the south-west geo-political zone has the highest number of medical schools in Nigeria, although the results of the distribution of respondents revealed a fair representation of the six geo-political zones of Nigeria. The finding that the medical school of graduation was the most common point of first contact between the respondents and physiotherapists might be due to the fact that the majority of the respondents graduated from medical schools that also had a physiotherapy training programme. The fact that the majority of the respondents graduated from medical schools with a physiotherapy training programme may also be responsible for the finding that the majority of the respondents viewed physiotherapy as both an arts and a science discipline.

More of the respondents graduated from universities that had a physiotherapy training programme. One possible reason for this may be because the majority of the respondents were from the south-west geo-political zone where universities with physiotherapy training programmes are concentrated.

The study also showed that the majority of the respondents who received some form of introductory lectures in physiotherapy during their medical training graduated from medical schools with a physiotherapy training programme. This category of respondents was of the opinion that physiotherapists are trained enough to determine the right treatment for their patients; they also felt comfortable enough to refer patients for physiotherapy. This finding agrees with those of Asem (2004) and Kerssens and Groenewegen (1990), who in their study on medical referrals to physiotherapy reported that physiotherapists are trained and qualified enough to make clinical judgements and to identify the problems of patients within their scope of practice.

About $80 \%$ of the respondents who received lectures in physiotherapy during their medical training referred patients for physiotherapy either occasionally or regularly without including a 'prescription' (of modalities) in the referral. While the majority of respondents who did not receive lectures in physiotherapy during their medical training rarely or never referred patients and a few of those who did refer patients included prescriptions in their referrals. This finding is corroborated by Fertig et al. (1983), who in their study titled 'Understanding variations in rates of referral among general practitioners in the United Kingdom', observed that the majority of the physicians that had received some lectures in physiotherapy referred more often, than those who did not receive any physiotherapy lectures. Fertig et al. (1983) also reported that the majority of physicians who did not receive any lectures in physiotherapy did not refer patients for physiotherapy at all.

The findings of the study also showed that the majority of the respondents who graduated from universities that had a physiotherapy training programme did not include prescription in their referrals while the majority of those who graduated from universities with no physiotherapy training programme included prescription in their 
referrals. This suggests that the 'university of graduation' of the respondents might have influenced the respondents' mode of referral of patients for physiotherapy, that is, their mode of use of physiotherapy whether as a 'prescription' rather than as a 'referral' on a consultation basis. The respondents might have acquired some knowledge of the role of physiotherapy in healthcare delivery during the period of their medical training which might have influenced their choice to refer patients for physiotherapy. This finding agrees with that of Kerssens and Groenewegen (1990) who observed that the majority of the physicians that agreed that physiotherapists are well trained graduated from medical schools with physiotherapy training programmes. The knowledge of the role of physiotherapy in health care delivery must have been acquired through the lectures received during their medical training and also through inter-professional clinical interactions with physiotherapists or physiotherapy students during ward rounds and clinical meetings. The possibility of interaction between the respondents and physiotherapy students is higher in universities with physiotherapy training programmes (Odebiyi et al., 2008).

The use of physiotherapy as a referral on a consultation basis rather than as a prescription by the majority of the respondents who graduated from universities with a physiotherapy training programme might therefore be due to the acquired knowledge on the role of physiotherapy in health care delivery. This may have been responsible for the non-inclusion of prescription in their physiotherapy referral, that is, their use of physiotherapy on a consultation basis. This must have also been responsible for the high rate of referral observed among these respondents. It has been shown that the awareness of the role of a profession in health care delivery may be a determining factor in the choice of its use (Jackson, 2004). According to Jackson (2004), lack of or poor knowledge about the role of a profession may not only lead to misconceptions about the profession, but may also lead to inter-professional conflict. Thus, the practice of including a prescription of modalities in 'physiotherapy referral' has been attributed to the wrong attitude and poor knowledge by physicians about the role of physiotherapy in health care delivery (Dunkel, 2004; Savinor and Shepherd, 2004). This finding is in agreement with the reports of Harrison (1975) and Waldman (2004), who reported that most physicians have very little or no knowledge of the profession of physiotherapy.

\section{CONCLUSIONS AND RECOMMENDATIONS}

The university of graduation of the respondents was found to influence the respondents' knowledge and perception of physiotherapy and this invariably affected both their use of physiotherapy and their mode of referral for physiotherapy (whether as a 'prescription' or a 'referral' on a consultation basis). It is recommended that medical schools without a physiotherapy training programme in Nigeria should endeavour to introduce one. Physiotherapy educators and/or clinicians should further educate physicians on the new trend of the role of physiotherapy in health care delivery, particularly during gatherings involving health providers, so that physicians who graduated from medical schools without physiotherapy training programme can have a better knowledge of the role of physiotherapy in health care, particularly in this era of collaboration. This will discourage the practice of using physiotherapy as a 'prescription' and encourage the use of physiotherapy as a 'referral', on a consultation basis as is practised in some developed countries.

\section{References}

American Physical Therapy Association. 1997. Guide to physical therapy practice. Physical Therapy 77 (11): IX.

Asem, A.L. 2004. Medical referrals to physiotherapy, do they tell you enough? Physical Therapy 74: 356-360.

Biddle, J. 1990. Physiotherapists as first contact practitioners. Developmental Medicine in Child Neurology 27(18): 104-124.

Balogun, J.A 1998. Physiotherapy; past, present and future. Physiotherapy Bud 1 (1): 6-7.

Dickson, D.A., C. Sanders and M. Maxwell. 2001. An evaluation of communication skills training for physiotherapy students. Medical Teacher 13 (4): 333-355.

Dunkel, B.H. 2004. Survey of attitudes of Arkansas physicians and physiotherapists, towards the professional capacity of the physiotherapist. Physiotherapy 25(18): 584-587.

Fertig, A., M. Roland, H. King and T. Moore. 1993. Understanding variations in rates of referral among general practitioners 27 (17: 1467-1470.

Gallery, P. 1990. Physiotherapist as a first contact practitioner; New challenges and responsibilities. Physical Therapy 2 (8): 246-251.

Harrison, F. 1975. Relationship between knowledge and utilization of physical therapists as reported by selected health-care team members. Unpublished B.Sc. Thesis Stanford University. 
Hogue, R.E. 2005. Physical therapy education; The present. Physical Therapy 10 (2): 300-355.

Jackson, D.A. 2004. Where is the physiotherapy profession going? Physiotherapy 22 (2): 400-455.

Kerssens, J.J. and P.P Groenewegen. 1990. Referrals to physical therapy; The relationship between number of referrals, indications for referral and the inclination to refer. Social Science Medical Journal 27(7): 797-804.

Lee, K. and L. Sheppard. 1998. An investigation into medical students' knowledge and perception of physiotherapy services. Australian Journal of Physiotherapy 4(4): 239-245.

McMeeken, J., G. Webb, K. Krause, R. Grant and R. Garnett. 2005. Learning outcomes and curriculum development in Australian physiotherapy education. The University of Melbourne. pp 12-13.

Odebiyi, D.O., Omotunde, A.O., Aiyejusunle, C.B., Olalekan, T.A. (2008. Knowledge and Perception of Physiotherapy by Final Year Medical Students of a Nigerian University. Nigeria Quarterly Journal of Hospital Medicine 18 (3), 158 161.

Quartey, J.N.A., C. Agbelie, B. Owusu-Ansah, A.I. Bello and K.O. Appiah-kubi. 2009. Content analysis ofphysicians' referrals to physiotherapy at Korle Bu Teaching Hospital Accra, Ghana. Ghana Journal of Physiotherapy 1(1): 10-12.

Ross, C.A., L.W. Roberts and T.T. Okson. 2000. The medical doctor-physiotherapist relationship; the physiotherapists' perspective. Physiotherapy 4(5): 219-223.

Savinor, G. and U. Shepherd. 2004. Physicians' knowledge and utilization of physiotherapy procedures. Physiotherapy 29(4): 44-46.

Sheppard, L. 1994. Changing the public perception of physiotherapeutic treatment. Health and Marketing Quarterly 12 (2): 77-95.

Silva, D.M. 2005. Californian physician professional image of physiotherapy. Physical Therapy 29(8): 1152-1156.

Struber, J.C. 2003. Physiotherapy in Australia - Where to now? The Journal of Allied Health Science and Practice 19(2): 10-25.

Waldman, M. 2004. Conflict of interest, physicians and physiotherapy. Canadian Medical Australian Journal 25(11): 1737-1739.

Wallace, A.S. 2003. Physiotherapy; its roles, rules and ethics. Australian Physiotherapy Association 24 (1): 71:5-18. 